\title{
Fiscalidad y poder. La fiscalidad centralizada como instrumento de poder en la Corona de Aragón (siglo XIV)
}

J. Angel Sesma Muñoz*

\section{LA MONARQUÍA Y LAS CLASES DIRIGENTES}

La Corona de Aragón es una formación política surgida al amparo de la reconquista para responder a un reto concreto. Su configuración espacial, lograda por acumulación de los territorios incorporados al dominio de un monarca, en algunos casos asignados a los primitivos núcleos en función de circunstancias coyunturales y sin ningún plan prefijado, concluye, a mediados del siglo XIII, con el establecimiento de tres estados peninsulares - los reinos de Aragón y Valencia y el principado de Cataluña- unidos por la soberanía común del rey, con fronteras interiores desdibujadas y con enormes problemas internos provocados por la necesidad de reorganizar la sociedad y las estructuras políticas a una nueva función, una vez agotada la expansión territorial.

* Universidad de Barcelona 
Los últimos decenios del siglo XIII transcurren en una rápida y a veces violenta reconstrucción de las relaciones '. El poder señorial se endurece y la pugna con el monarca conduce a la nacionalización de la nobleza, que en cada territorio tenderá hacia una política de poder compartido, donde el rey debe aceptar un corpus jurídico basado en los antiguos fueros frente a su interés por implantar el Derecho Romano, y admitir la formación de una Curia amplia, las Cortes, donde las clases dirigentes tradicionales y los nuevos poderes ciudadanos, intervienen en la política exterior, controlan la organización fiscal y participan en la armonización, en su propio beneficio, de la convivencia interna, tanto respecto a la monarquía, como a sus vasallos; se llega a establecer, aunque nunca a ponerse en práctica, como manifestación de este poder compartido, la obligatoriedad de reunir periódicamente las Cortes y la incapacidad del rey de actuar sin su conocimiento.

La nobleza tradicional, cortadas sus posibilidades expansivas y agotada la fuente principal de su crecimiento, la guerra de conquista, se ve obligada a retroceder y buscar la solución en sus posesiones, con la ampliación de sus prerrogativas y el aumento de los beneficios a costa de sus vasallos, pero para ello necesitaba de la monarquía y de la nueva fuerza emanada de las ciudades; se hacía preciso ampliar la cúpula de poder y proceder a una revisión de las fuentes de ingresos, mejorando los métodos de exacción por los que pasaban a sus manos los excedentes y, finalmente, establecer un sistema de distribución concertada de los mismos, evitando los enfrentamientos entre los integrantes de esa cúpula.

Para ello las antiguas Curias se convertirán en el escenario político donde se aglutinarán las fuerzas de cada territorio y se regularán las relaciones entre el rey y los poderes estamentales y las de éstos entre sí. Siempre convocadas y presididas por el rey, «pro bono estatu prospero et tranquillo regni nostri» $y$ «ad tranquillitatem subditorum nostrorum... ut ipse vivant in tranquillitate pacis et inter eos justicia

1 Se aborda el paso de una economía de guerra a una economía de paz, que si a la inversa, según E. PERROY, "A l'origine d'une economie contractée: les crises du XIV siècle", Annales ESC, 1949, p. 172 y aceptado por G. Bois, Crise du féodalisme. Economie rurale et démographie en Normandie du début du XIV siècle au milieu du XVI siècle, Paris 1976, $\mathrm{p}$. 251 , es un factor fundamental en el desarrollo y solución de la crisis feudal del siglo XIV, en el sentido recorrido en la Corona de Aragón a mediados del XHI alteraría los sistemas de poder establecidos desde la centuria anterior y abriria un proceso de modificación en la diferenciación social hasta entonces vigente. 
conservetur", como repetidamente señala en sus cartas de llamamiento y en los parlamentos de apertura, las escasas reuniones celebradas durante casi toda la primera mitad del siglo XIV, no son perturbadas por desavenencias, ni siquiera las demandas reales de servicios extraordinarios alteran el equilibrio, pues son concedidos sin la menor resistencia a base de imposiciones también extroardinarias, a cambio de prerrogativas $y$ beneficios legales ${ }^{2}$.

Pero esta tranquilidad, cuya conservación es casi una obsesión de la monarquía, es ficticia. Por debajo del caparazón mostrado en las reuniones se agudiza la crisis general y se limitan los recursos globales de buena parte de los integrantes del grupo dirigente, es decir, se altera el reparto de poder aceptado y defendido, con los consiguientes movimientos no sólo interclasistas, sino entre los componentes de esa aristocracia, a la búsqueda de un nuevo equilibrio. El grado de incidencia de los múltiples factores que intervienen en el desarrollo de la crisis variará de un territorio a otro, aunque el idéntico sistema socio-económico, contribuye a que el resultado final sea el mismo: papel creciente del comercio y necesidad de recurrir a un modelo de feudalismo centralizado como estructura global de la sociedad ${ }^{3}$.

Será precisamente en el control del poder central donde primero se producirá la ruptura. La nobleza más tradicional en Aragón y Valencia desempolvará en 1347 el espíritu de la antigua Unión y con un pretexto sucesorio intentará un asalto al poder real. El fracaso es absoluto; al basar sus planteamientos en puntos de estricta defensa estamental - de

2 Para Aragón puede verse el excelerite estudio de L. GonZÁLEZ ANTÓN, «Las Cortes aragonesas en el reinado de Jaime II», AHDE, XLVII (1977), pp. 523-682.

${ }_{3}$ Las alteraciones de precios y salarios, los traslados de la población rural hacia las ciudades y el incremento de la presión señorial para evitarlos son rasgos intuibles en la Corona de Aragón, aunque la falta de estudios precisos impide un análisis más completo. Conviene recordar la bibliografía que al respecto ha dedicado la historiografía europea, desde los primeros planteamientos de $E$. PERROY, en el artículo citado anteriormente y $R$. HILTON, «Y eut-il une crise générale de la féodalité?», Annales ESC, 1951, ahora incluido en una recopilación de sus trabajos bajo el expresivo título de Class Conflict and the Crisis of Feudalism, Londres 1986 (trad. al castellano ed. Crítica, Conflicto de clases y crisis del feudalismo, Barcelona 1988), y las posteriores aportaciones de G. DuBY, L'économie rurale et la vie des campagnes dans l'Occident médieval, Paris 1962, y E. Le Roy LaduRIE, Paysans du Languedoc, Paris 1966, hasta las más recientes de G. Bols, Crise du féodalisme, cit. supra, "Against the neo-malthusian ortodoxy", Past and Present, 79 (1979) y las de R. BRENNER «Agrarian class structure and economic development in preindustrial Europe», Past and Presente, 70 (1976) y «The agrarian roots of the European capitalism», Past and Present, 97 (1982), entre otros. 
su estamento nobiliar- no contarán con otros apoyos y el bando realista obtendrá una victoria militar que permitió a Pedro IV una dura represión entre los principales implicados, aunque no pudo, por el resto de los factores ya desencadenados, transformar el sistema.

Por una parte, la derrota de esta segunda Unión coincide con la explosión de la Peste Negra, el gran colapso demográfico y el consiguiente aumento de la movilidad poblacional. En los dominios señoriales descenderán las rentas ${ }^{4}$ y en los medios urbanos no se podrá evitar, especialmente en Barcelona, la quiebra de las fortunas apoyadas en el gran comercio mediterráneo. Pero, como contrapartida, en muy corto plazo de tiempo, en las tierras interiores la agricultura experimentará una profunda transformación, con el abandono de espacios marginales que se dedicarán a pastos para una creciente cabaña lanar y con la intensificación de cultivos específicos, exportables junto con la lana, a través de los mercados comarcales hacia los circuitos europeos ${ }^{5}$. La mejora de la situación económica general, observable al cabo de pocos años, afectará muy directamente a las economías medianas rurales y urbanas, dejando al margen a los señores, cuyas rentas estaban aferradas a conceptos antiguos ${ }^{6}$.

Por otra parte, se abrirá un prolongado estado de guerra, durante el cual la monarquía aragonesa sin patrimonio propio y con muy limitada capacidad de convocatoria de tropas, pasará a depender de las concesiones extraordinarias otorgadas por las Cortes a cambio, siempre, de contrapartidas especiales. Las guerras del rey, tanto si se trata de defender las posiciones mediterráneas (sublevación de Cerdeña, guerra con Génova), como la integridad de las fronteras peninsulares (guerra de los Dos Pedros), se convierten en instrumentos esgrimidos por los grupos dominantes de los reinos para presionar al rey e incrementar su participación en el reparto del poder.

${ }^{4}$ De esta caída de las rentas fueron víctimas todos los nobles, aunque en grado variable según el lugar, el momento y la diferente feudalización de la sociedad (G. BoIs, "Noblesse et crise des revenus seigneuriaux en France aux XIV et XV siècles: essai d'interpretation", en La Noblesse au Moyen Age, Paris 1976, p. 226).

5 Un planteamiento general que permite iniciar la investigación de este fenómeno en Aragón en J.A. SESMA MUÑOZ, Transformación social y revolución comercial en Aragón, durante la Baja Edad Media, Fund. Juan March, Madrid 1982.

6 El derrumbe económico de la nobleza no está solamente ligado a una profunda crisis social, es también el resultado 0 , si se prefiere, el "momento crítico" de un largo proceso nacido con el propio sistema social (G. Bols, "Noblesse et crise des revenus...", cit., $p$. 231). 
Los últimos cuarenta años de su reinado los pasó Pedro IV en discusiones con las fuerzas sociales reunidas en Cortes, en solicitud de ayudas financieras para hacer frente a las guerras. Su posición era siempre de debilidad, porque siempre comparecía atosigado en su territorio por ejércitos mejor dotados y organizados y las concesiones que obtenía, largamente negociadas, serán siempre «non ex debito, sed solum ex providentia et mera voluntate" ${ }^{7}$. En estas condiciones las Cortes se convertirán en el engranaje entre el monarca, que necesita dinero, y el cuerpo social que lo aporta, lo que da una fuerza política desconocida hasta entonces a los representantes estamentales ${ }^{8}$.

Pero además, esta intervención en la gestión fiscal servirá a los grupos dirigentes reunidos en Cortes de llave para abrir una nueva vía para solucionar la caída de sus rentas. Sin renunciar a éstas y sin modificar los otros sistemas de exacción, dispondrán de una fiscalidad centralizada, dispuesta por la máxima autoridad, el soberano, a la que nadie puede sustraerse, pues se presenta como necesaria para la defensa de la comunidad y protección de los habitantes. La guerra, ya sin solución de continuidad ${ }^{9}$ pasaré a ser un componente imprescindible que obliga a la monarquía a solicitar continuos subsidios y, al mismo tiempo, es un instrumento de presión para obtenerlos ${ }^{10}$.

El proceso, en sus líneas generales, es similar al emprendido en Occidente como medio para superar la crisis feudal y será uno de los

7 Esta fórmula utilizada de manera casi ritual, se completa con otras más espontáneas, como la expresada por los aragoneses en la reunión de Cariñena de 1357, cuando al otorgar ayuda al monarca para defender las propias fronteras dicen hacerlo crequeridos y rogados por el dicho rey, no forzados sino por si mesmos y porque el senyor rey les tenga que agradecer" (A. SeSma-E. SARASA, Cortes del reino de Aragón, 1357-1451. Extractos y fragmentos de procesos desaparecidos, Valencia 1976, p. 29); similar a lo expresado por los catalanes en las de Tortosa de 1365, haciendo constar que la ayuda concedida para la guerra con Castilla, la hacen "graciosament e no per algun deute quen fos tenguda e obligada" (CORTES DE CATALUÑA, t. II, p. 255) y por los valencianos en las de Valencia de 1360 , cuando cada brazo obliga al rey a aceptar una cláusula señalando «que per lo present otorgament, to qual fan graciosament, nols sie feyt preiudici" (S. ROMEU, "Cortes de Valencia de 1360", AHDE, XLIV (1974), p. 691).

${ }^{8}$ En Castilla, para entonces, estaba ya constituida una potente Hacienda Real a través de la cual los reyes contaban con una fuerza fiscal estable y autoridad reconocida para el manejo de los fondos obtenidos (M.A. LAREDO QUESADA, "Instituciones fiscales y realidad social en el siglo XV castellano", El siglo XV en Castilla, Barcelona 1982, p. 59).

${ }^{9}$ De manera ininterrumpida se prolongará el estado de guerra o de inestabilidad militar, tanto frente al exterior, sobre todo con Castilla y Francia, como en el interior: interregno, sublevación del conde de Urgel, levantamiento de Cataluña, etc.

${ }^{10}$ La guerra como medio de frenar los problemas económicos de la nobleza y, además, para recuperar parte del prestigio perdido, en G. Bols, «Noblesse et crise des revenus», cit., p. 228. 
cauces de transformación de las estructuras políticas hacia la creación del Estado Moderno o absoluto ${ }^{11}$, entendiendo como tal el cuerpo político caracterizado por ser una organización capaz de ejercer y controlar el uso de la fuerza sobre un pueblo determinado y en un territorio dado.

La toma de posiciones por parte de los grupos de poder en la Corona de Aragón fue rápida y con acciones efectivas para el mejor aprovechamiento de la situación en su beneficio. Junto a los objetivos eminentemente políticos emprendidos en muchos casos conjuntamente ${ }^{12}$, se desarrollarán los mecanismos propios suplantadores de la fiscalidad del rey, que no llegará a ser regular, lo que frenará de manera definitiva el fortalecimiento de la monarquía. Pero la existencia de los tres núcleos territoriales antiguos, con una separación de tipo nacionalista consecuencia de la política interior seguida por Jaime I, frustrará una posible organización unitaria, con matices federalistas, intentada desde intereses económicos, que hubiera desembocado en un estado único y llegado a constituir la auténtica Corona de Aragón, necesaria en el entorno en el que se debería desenvolver, pero que políticamente llegaba tarde en las postrimerías del siglo XIV.

Finalmente, el impulso nacido de la nueva fiscalidad conducirá a la formulación de tres Estados cuyo único nexo será la monarquia común, aunque la triple corona que portaba le limitará el valor emblemático que la realeza iba adquiriendo en Occidente; en su lugar, el concepto de reino, es decir, del conjunto de la sociedad aglutinada en torno a las instituciones representativas, como símbolo del bien común, adquirirá fuerza y vigor, lo que será capitalizado por los grupos de poder en su beneficio, así en sus planteamientos frente al rey como en el seno de la sociedad.

11 Territorio y lengua, religión y civilización, ideas de interés nacional y honor, la organización del Estado y la estructurá de la sociedad son, en gran medida, productos de guerras (F. HerTz, Nationality in History and Politic, Nueva York 1944, p. 217). La importancia de la guerra en todo proceso de este tipo queda de manifiesto en K.B. MACFARLANE, England in the fifteenth century, Londres, 1981, colección de artículos entre los que puede destacarse. "War, the economy and social change: England and the Hundred Years War", pp. 139-150. Por supuesto es fundamental la obra de PH. CONTAMINE, Guerre, état et société à la fin du Moyen Age, Paris-La Haya, 1972.

${ }_{12}$ Remito a mi ponencia "Cortes Generales y monarquía. El poder político en la Corona de Aragón a finales del siglo XIV", presentada en el Congreso sobre Los origenes del Principado de Asturias y de la Junta General celebrado en Oviedo (diciembre 1988) dentro de los actos conmemorativos del VI Centenario del Principado de Asturias, y cuyas actas se publicarán en breve. 
El desarrollo institucional a partir de estos principios tenderá, en los tres estados simultáneamente, a ser idéntico, absolutamente simétrico, buscando en ese paralelismo la más completa diferenciación y aportando, como una baza más para conseguir el control social, una elevada dosis de nacionalismo en todas las manifestaciones políticas, económicas y sociales ${ }^{13}$.

\section{LA FORMULACIÓN DE UNA NUEVA FISCALIDAD}

El período de guerras abierto inmediatamente después de la Peste Negra y el triunfo sobre la Unión iba a tener su punto culminante en el enfrentamiento con Castilla. Desde los comienzos el rey se encontrará en continuo agobio militar para defender las fronteras de los reinos peninsulares, lo que le obligaba a constantes peticiones de auxilio para mantener su ejército. En los cinco primeros años de la guerra Pedro IV había recurrido a todos los resortes posibles para obtener la financiación extraordinaria y urgente necesaria. Las Cortes y los parlamentos particulares de sus reinos, le habían otorgado generosas ayudas, que se pueden calcular en unas 220.000 libras los catalanes y 200.000 libras los aragoneses y valencianos. La concesión de estas cantidades representaba una presión fiscal suplementaria superior a una libra por hogar y año, lo que añadido a las imposiciones y derechos reales, señoriales, municipales y eclesiásticos, significaba estar sometiendo a la sociedad a un esfuerzo difícil de mantener, máxime si tenemos en cuenta el reciente impacto de la peste y que una porción del territorio estaba sufriendo los efectos de la guerra.

Para paliar en parte este exceso que podía afectar al resto de las percepciones, en cada concesión los brazos individualmente y las Cortes en su conjunto, habian ya introducido unas normas para frenar las exigencias reales. Es el caso de los catalanes en Cervera (1359), que con la aprobación de 72.000 libras anuales durante dos años consiguieron

${ }^{13}$ Cfr. mis trabajos «Estado y nacionalismo en la baja Edad Media. La formación del sentimiento nacionalista aragonés", Aragón en la Edad Media, VII (1987), pp. 245-273, y "El sentimiento nacionalista en la Corona de Aragón y el nacimiento de la España moderna", en Realidad e imágenes del poder, Valladolid, 1988, pp. 215-231. 
del rey su compromiso de abstenerse en ese plazo de reclamar otros auxilios, no forzar a nadie por razón de hueste, ni obligar a hacerle préstamos, junto con medidas jurisdiccionales que garantizaban los privilegios y libertades de los ciudadanos ante la presión del soberano ${ }^{14}$.

Pero, sobre todo, las Cortes habían impuesto modificaciones en los sistemas de recaudación para poder controlar ésta y en lo posible recuperar para sí una parte de las ayudas. Esa misma reunión de Cervera, como las inmediatas de Zaragoza y Valencia de $1360^{15}$, recogiendo y concretando las condiciones lentamente introducidas en anteriores concesiones, adjudicaron a los brazos el control absoluto del fogaje aprobado para ayudar al rey; para ello, cada grupo, independientemente, designaría administradores, oidores de cuentas y consejeros, con amplios poderes para el cobro en sus propios dominios y para la gestión e inversión directa de la parte recaudada según lo decidido por la asamblea. Su actuación quedaba sujeta únicamente a la autoridad del brazo respectivo y, a través de él, de las Cortes, hasta el punto que los designados podian extender documentos y sellarlos con el sello de las Cortes y en caso de paz o tregua duradera conservar las cantidades percibidas y no gastadas. Se prohibía la intervención del rey y sus oficiales, que quedaban alejados del proceso y si reclamaban la presencia de los administradores fuera del propio territorio, se supone que para poder presionarlos aisladamente, ipso facto cesaba la ayuda.

Estamos, pues, ante una profunda alteración del mecanismo de recaudación y en el germen del cambio de sistema de administración. Se concede graciosamente al soberano una ayuda a través de un impuesto extraordinario aplicado en todo el territorio, pero se aparta del manejo del dinero al rey y a sus oficiales, es decir, se trata de una forma de fiscalidad centralizada, aunque el destinatario no es la Hacienda real, pues cada estamento con jurisdicción lo cobra en sus tierras, en nombre de la monarquía y para defensa del bien común, convirtiendo, además, a sus gestores en administradores de las cantidades recaudadas. Con esta operación los señores exigen de sus vasallos las cantidades necesarias para que el rey disponga de un servicio de armas que ellos mismos le

14 Cortes de Cataluña, t. III, pp. 375-420.

15 Un resumen muy esquemático del proceso de las Cortes de Zaragoza en A. SESMAE. SARASA, Cortes del reino de Aragón, cit., pp. 39-42. La edición de las valencianas en S. ROMEU, Cortes de Valencia de 1360, cit., pp. 675-711. 
prestan, con lo que el impuesto recaudado recaerá en última instancia en las rentas del señor, en función de su participación militar.

Desde comienzos del siglo, en el transcurso del ejercicio de ese poder compartido, se había desarrollado un sentimiento de unidad entre los representantes de los diferentes estamentos. Aunque estaban en las Cortes a título individual y por su situación en el tejido social superior, se empezaba a perder el antiguo espíritu de las curias feudales y pasaban a identificarse, como cuerpo, con el conjunto del reino, con el símbolo de ese nacionalismo incipiente, frente al poder del rey. Esto queda plasmado en el concepto de «General» que se utiliza para denominar al bloque que representa en las Cortes la parte que no es la monarquía. Así, ya en las de Barcelona de 1347 se señala "erat Generale Cathalonie congregatur, scilicet, prelati, barones, milites, cives et homines civitatum et villarum Cathalonie, et sindici capitulorum ecclesiarum ac universitatum et civitatum et villarum predictorum ${ }^{16}$.

Esto no significa la simple existencia de dos bloques opuestos, reyreino, en el seno de las Cortes, ni que se haya eliminado el enfrentamiento estamental, porque de hecho la insolidaridad de los brazos con jurisdicción con respecto al ciudadano en los repartos de las cantidades ofrecidas es manifiesta, así como la mayor presión ejercida por el monarca sobre el llamado brazo real, lo que queda reflejado en el hecho de que a las Universidades, con un escaso 35 por 100 de los fuegos ${ }^{17}$, se les asigne habitualmente más de la mitad del importe total de las concesiones, sin que las protestas y los recursos al soberano consigan modificarlo, como se comprueba en las Cortes aragonesas de 1367, cuando ante la violenta discusión por el reparto entre nobles y ciudadanos el rey les hace salir de la sala y dicta una sentencia, con ayuda de los demás estamentos y del Justicia de Aragón, tan perjudicial para ellos que con amargura le responden que «como todos los tres barços habiessen siempre feyto part contra el dito braço de las Universidades, que toda hora

${ }^{16}$ A. de la TORRE, Origenes de la Diputación del General de Catalunya, Barcelona 1923 , p. 21. Un comentario crítico de este estudio, que aclara conceptos y completa la evolución de la institución, a cargo de J.M. Ramos LosCERTALES, AHDE, II (1925), pp. 553* 554.

17 Para Aragón, según el cálculo de las Cortes de Zaragoza de 1364, el 23 por 100 de los fuegos del reino pertenecian al estamento eclesiástico, el 42 por 100 a ambas noblezas y el 35 por 100 al de Universidades (A. SEsma-E. SARASA, Cortes del reino de Aragón, p. 58). En Cataluña, en las Cortes de Barcelona de 1377-78, se declara que del total de 78.170 fuegos, la Iglesia dispone del 26 por 100 , la nobleza del 36,5 por 100 y el brazo real del 37,5 por 100 restante (CORTES DE CATALUÑA, t. IV, pp. 1-85). 
que havies a clamar Corts, fizies clamar a los de las ditas Universidades por un cabo et ellos apart ferli han aquella proffierta que podiessen, que do mal tractados haviessen a seer, querianlo seer mas por el senyor rey, que no por los ditos tres braços» ${ }^{18}$.

La actitud de los estamentos superiores, aunque no de forma desinteresada, apuntaba hacia una realidad cada vez más manifiesta. Desde la crisis de mitad del siglo, el auténtico crecimiento económico estaba más unido a las actividades mercantiles e industriales y la posibilidad de incrementar la presión fiscal no radicaba en multiplicar los cobros a los campesinos, sino en buscar las vías adecuadas para hacer cotizar la producción artesanal y la circulación de mercancías, lo que sólo podía hacerse con la participación de las oligarquías urbanas.

Y en esa dirección actuarán las Cortes Generales reunidas en Monzón en $1362{ }^{19}$, que marcarán el punto culminante de la transformación fiscal. Convocadas por Pedro IV de Aragón en el momento de mayor agobio en su enfrentamiento con Pedro I de Castilla, congregan en una misma asamblea a los estamentos de sus estados peninsulares y del reino de Mallorca, lo que da idea de la importancia asignada al problema y del interes del rey y de los reinos para tomar decisiones al máximo nivel, el de toda la Corona.

La gran novedad consistirá en la introducción de un nuevo concepto fiscal, llamado "Generalidades» en directa alusión al "General» de quien dependía, consistente en la aplicación de una tasa sobre la producción textil interior y sobre el comercio de exportación, exigible en todo el territorio de la Corona, por encima de divisiones señoriales y de jurisdicciones y a toda persona que sacara mercancía por las fronteras, cualquiera que fuera su estatus social, pues incluso el rey y su familia estaban obligados al pago.

La primera regulación aprobada en 1362 , todavía era muy tímida y se introdujo como complemento de una tradicional concesión de fogaje; se presentó a iniciativa del General de Cataluña, siendo bien recibida por el valenciano y sólo aceptada tras iargas discusiones y con muchas reticencias por los brazos aragoneses. Su articulación corresponde a un muy

${ }^{18}$ Archivo Diputación Zaragoza (ADZ), Actas de las Cortes de 1367, ms. 1, f. 157 v.

19 La edición de las actas a cargo de José M. Pons GuRl, en el vol. L de la Colección de Documentos Inéditos del Archivo de la Corona de Aragón, Madrid-Barcelona 1982. 
bien estructurado análisis de la situación económica y política y podría ser obra de expertos hombres de negocios y de teóricos catalanes de la política.

La tasa exigida a ciertas mercancías para su salida del espacio de la Corona, no perjudicaba el mercado interior, ni tampoco gravemente al exterior, pues al ser su arancel ad valorem, acumula mayor carga fiscal en los productos de alto precio con un comercio garantizado, mientras los modestos quedan mucho menos afectados; la fijación de los puntos de cobro en el perímetro exterior del territorio de la Corona, con especial atención a los puertos mediterráneos y a los pasos pirenaicos, sin incidir en los intercambios internos, contiene una formulación de espacio económico único, definido por el impuesto y por las medidas proteccionistas en favor de una distribución coherente de las actividades económicas prioritarias, al contribuir a que la producción de materias primas se concentre en las tierras interiores y complemente a la industria de transformación y al comercio asentado en las áreas marítimas.

En cuanto al gravamen sobre la manufactura textil, se establecía también con carácter general en toda la Corona, sin excepciones por cuestiones jurisdiccionales y afectaba al conjunto de la industria pañera, cualquiera que fuera su volumen o calidad. El sobrecargar la producción de tejidos con una tasa constituía una grave decisión en un momento en que las perturbaciones exteriores habían cerrado parte del mercado tradicional catalán y cuando la competencia extranjera en paños de calidad y precios medios, podía alterar negativamente la economía del principado. Para compensar el sacrificio exigido, el acuerdo de las Cortes Generales incluye la prohibición de importación de tejidos y la obligación de todos los habitantes de la Corona, desde el monarca al último de los vasallos, de vestir y consumir sćlo los de elaboración interna, lo que esconde una política de fuerte proteccionismo en beneficio de los industriales catalanes, únicos capaces de atender una demanda tan amplia y variada. Se les hace abandonar los mercados exteriores, donde habían perdido ya buena parte del negocio, y se les garantiza el monopolio de los interiores, que se encuentran en franca expansión. 


\section{EL CONTROL DE LA FISCALIDAD IMPULSA LOS PARTICULARISMOS}

«Es assi avenido por la Cort que todas las dictas Generalidades sian levadas e collidas en los regnos de Aragon, de Valencia e principado de Cathalunya e en el regno de Mallorches en la forma susodicta, es assaber, por mano e ordenacion de los dipputados de cada un regno o por aquellos qui por ellos hi seran assignados, los quales dipputados sian tenidos por virtut del sagrament e homenatge que han feyto o deven fazer, que aquellos los plegaran e faran collir e plegar como mellor e mas proveytosament podran e quen daran buen conto e leal, es assaber, el un regno al otro, segund que fazer se deve e yes avenido".

En este acuerdo de las Cortes Generales de Monzón quedan establecidas las Generalidades y las Cortes se convierten en responsables directas de una gestión fiscal. Al lado de la fiscalidad del rey, de los señores, de los municipios y de la Iglesia, nace la del reino, independiente de aquéllas, de base mucho más amplia y sin ningún tipo de incompatibilidades. Se hace preciso, pues, que las Cortes generen un órganio encargado en su nombre de cobrar y administrar los ingresos y de dar cuenta de su gestión a los demás reinos de la Corona, ya que debido a la existencia de tres "Generales" era impensable mantener en este aspecto la idea de espacio único aplicada en la definición y regulación de los conceptos fiscales, aunque también aquí la normativa aprobada deja entrever una madura elaboración y un objetivo unificador.

Se procede, en consecuencia, a la creación de tres órganos representativos, llamados Diputaciones, correspondientes a cada uno de los estados peninsulares -Aragón, Valencia y Cataluña-, con una composición paritaria de todos los estamentos y con el poder recibido de las Cortes para cobrar y administrar las Generalidades y demás ingresos destinados a sufragar la guerra. Al mismo tiempo, se constituye una colegiación de los tres, en forma de consejo integrado por representantes de cada una de las Diputaciones, que desempeñará la función unificadora, pues recibe el encargo de modificar y perfeccionar el sistema, decidir en las cuestiones provocadas por su aplicación y distribuir las cantidades recaudadas en concepto de aduanas, con el fin de compensar a Aragón, que al ser territorio interior y tener menor capacidad exportadora directa obtendría menores ingresos. Este órgano superior se reunirá 
anualmente en Gandesa y al recibir las cuentas de las tres gestiones actuará como velador de la recta aplicación de la nueva fiscalidad.

Parece claro, pues, que el impuesto al comercio y la protección a la industria textil sirven para dibujar un espacio económico-fiscal único, similar al político de la Corona. El establecimiento de las Diputaciones, el consejo de representantes y el sistema compensatorio de los ingresos por aduanas intenta fijar unas relaciones institucionales aunadoras de intereses sociales y económicos de los grupos dirigentes de los tres estados. Los pasos iniciados en 1362 en Monzón parecen apuntar, en un plazo breve de tiempo, al establecimiento de un espacio económico sólido, que pudiera servir de base a un futuro espacio nacional coincidente con el de la Corona.

La elaboración del proyecto y la forma de exponerlo y hacerlo aprobar por el monarca y las Cortes, ponen de manifiesto que no es fruto de la casualidad ni de la improvisación, aunque sí, probablemente, llegaba en un momento poco propicio. Los barones en general, y quizá más claramente los aragoneses, no parecian dispuestos a compartir la jefatura política que junto al rey desempeñaban, especialmente en un momento de guerra; en los aspectos económicos, la oferta catalana marginaba excesivamente el desarrollo interno de la burguesía urbana de Aragón y obligaba al reino a aceptar unas relaciones coloniales de mero productor; además, el beneficio inmediato que los brazos aragoneses podían obtener por la aplicación de la nueva fiscalidad era muy pequeño, pues al no disponer de manufactura textil, los ingresos del General de Aragón se reducian a las modestas transacciones con Navarra, Castilla y sur de Francia, cuyas fronteras eran impracticables por la guerra ${ }^{20}$.

Así, pues, no debe extrañar la breve vigencia de estos acuerdos. Sólo dos años después de la reunión de Monzón, al concluir exactamente el período allí pactado, el General de Aragón reunido en Cortes en Zaragoza, reforma los puntos fundamentales de aplicación para adaptar el nuevo sistema fiscal a los intereses particulares de los grupos dirigentes del reino. Se sigue manteniendo la tasa de aduanas, pero haciéndola extensiva a todos los productos exportados, excepto la sal y el vino (producciones eminentemente señoriales) y, además, se exigirá en las fron-

${ }^{20}$ Los importes que se recaudan por la Hacienda aragonesa en los primeros años de aplicación de las Generalidades serán de 210 a 250 libras mensuales, según se deduce de las inversiones y pagos realizados por las Cortes. 
teras propias, lo que incorporaba las salidas a Valencia y Cataluña; se autoriza la entrada y venta en el reino de paños extranjeros, entre los que se cuentan los del principado, pero recargan la importanción con una fuerte imposición equivalente al 10 por 100 de su valor; simbólicamente, se mantiene el impuesto sobre la industria pañera, pero entregando los beneficios a los municipios ${ }^{21}$.

Soluciones similares adoptaron los valencianos en ese mismo año 1364, obligando a los catalanes, en 1365, a reconsiderar también el plan original y modificarlo en el mismo sentido, aunque estuvieron a punto de llevar más lejos la reforma fiscal, pues en esas Cortes el brazo de Universidades presentó una propuesta consistente en la eliminación de fogajes, Generalidades y demás sistemas de exacción centralizada, y aplicar exclusivamente una especie de tasa a los rendimientos personales, basada en la contribución general de todos los habitantes del principado, sin importar ley, estado o condición, de una única imposición equivalente a la onceava parte de las ganancias obtenidas por cualquier concepto a lo largo del año ${ }^{22}$.

Esta proposición revolucionaria, que hacía surgir en pleno siglo XIV una fiscalidad directa de un sólo concepto, general para todo el cuerpo sociai y proporcional a los beneficios anuales obtenidos, no fue tenida en cuenta por los estamentos superiores, que prefirieron seguir defendiendo las tasas indirectas y los fogajes y repartos como fuentes fiscales centralizadas, tanto del monarca como del reino.

\section{LA FISCALIDAD DEL GENERAL, INSTRUMENTO DE PODER}

Con la reordenación particular quedan dibujados en la Corona de Aragón tres espacios económico-fiscales coincidentes con los tres estados peninsulares, dotados ahora de fronteras bien definidas por una tupida red aduanera. En cada uno de estos territorios una institución, la Diputación, regida por los dirigentes de cada estamento, adquiere amplia

21 J.A. SESMA MUÑOz, «La fijación de fronteras económicas entre los estados de la Corona de Aragón», Aragón en la Edad Media, V (1983), pp. 141-163.

22 Cortes de Cataluña, t. II, pp. 354-355. 
jurisdicción para regular la fiscalidad propia en función de sus intereses propios.

Sin embargo, a pesar de la autonomía alcanzada, el sistema sigue apoyando su razón de ser en la obligación de prestar auxilio al rey en la guerra, es decir, continua sin despegarse de la componente inicial de necesidad del soberano. Para culminar el proceso y satisfacer plenamente los intereses de los grupos dominantes este impuesto extraordinario debía convertirse en ordinario y regular y, además, cambiar el argumento justificativo de su aplicación; desde la defensa del territorio, que podía esgrimirse esporádicamente y exigía, además, la colaboración de la monarquía, debía pasarse a la defensa del orden interno y de las libertades de los regnícolas, concepto más difuso y más acorde con la evolución del nacionalismo que desde las clases dirigentes se canalizaba e impulsaba.

Cataluña, que había demostrado mayor actividad y sus dirigentes una más clara identidad de intereses, toma, como en las etapas anteriores, la iniciativa. Para conseguir la fijación del impuesto y su organización administrativa, el General buscó la fórmula de condicionar la recaudación a un fenómeno más constante y menos gravoso que la guerra y que pudiera renovarse continuamente, hasta hacerlo ordinario y regular. La emisión por las Cortes de $1365^{23}$ de una elevada cantidad de censales cargados sobre los bienes del General, es decir, del conjunto de la sociedad catalana, y cuyos intereses anuales se abonarian con el importe obtenido de las Generalidades, era la fórmula más lúcida entre las posibles, pues involucraba a todos los estamentos del principado en una deuda que sólo las Cortes podían hacer crecer o menguar, aplicable a voluntad y practicamente inextinguible, lo que garantizaba la continuidad de la necesidad del impuesto y del aparato administrativo.

Aragón y Valencia tardaron aún unos años en seguir el mismo modelo ${ }^{24}$, pero finalmente crearon la deuda del reino e integraron el producto del impuesto de Generalidades al pago de sus intereses anuales. Desde el primer momento la deuda del General experimentó en todos los

23 Cortes de Cataluña, t. II, pp. 390-398.

${ }^{24}$ En las Cortes Generales de Monzón celebradas en 1376, que otorgaron al rey un auxilio económico importante, los brazos aragoneses decidieron que las 78.000 libras que aportaban se obtuvieran de la emisión de censales sobre los bienes del General de Aragón con un interés anual del 10 por 100 abonable con los ingresos de las Generalidades nuevamente aprobadas ( $A D Z$, Actas de las Cortes, ms. 2). 
estados un continuo crecimiento debido a la constante emisión de censales por las Cortes para satisfacer rápidamente las necesidades financieras del rey o de los reinos y, por consiguiente, el cobro de las Generalidades se hizo ordinario y regular y rentable, aunque durante los primeros decenios sus rendimientos eran modestos.

Las Diputaciones, creadas inicialmente como meras gestoras temporales del impuesto, adquirieron muy pronto el carácter permanente que exigia el pago de los intereses anuales de la deuda ya firmemente establecida; al mismo tiempo, sus atribuciones financieras se fueron cargando de poder político y paulatinamente se desligaron de las Cortes y se erigieron en el único organismo representativo que en cada uno de los estados de la Corona era de composición estamental, paritario y permanente, con capacidad de actuación en todo el territorio, encargado de la defensa de los intereses comunes y con medios económicos para adoptar medidas en favor de esos intereses ${ }^{25}$.

En el equilibrio de poder establecido desde finales del siglo XIV y que se mantendrá al menos durante cien años, las Diputaciones del General se constituyen en los centros neurálgicos de las relaciones con la monarquía y en los núcleos de control de la política interior de los reinos. En el entramado nacionalista ya perfectamente ordenado, la Diputación será la depositaria de las esencias comunes y la defensora de las libertades de la tierra; en lugar del rey, simbolizará al propio “reino» como Estado ${ }^{26}$.

En tan solo cincuenta años y con el impulso de la transformación fiscal, en la Corona de Aragón se pasa del modelo de soberanía absoluta expuesto por Pedro IV en las Ordinaciones del Condestable ${ }^{27}$, donde la

25 Un análisis de esa trayectoria, para la Diputación de Aragón única de las tres estudiada con detalle, en la primera parte del libro de J.A. SESMA y J.A. ARMLLAS, El gobierno de Aragón. De la Diputación del reino a la Diputación General, Zaragoza 1989.

${ }_{26} \mathrm{Ni}$ siquiera cuando desde finaies del siglo XV la bancarrota de sus Haciendas las sometan al arbitrio de Fernando II (J. ViNCES VIVES, «El 'redreç" de la economía catalana de 1481", Studi in Onore di A. Sapori, Milán 1957, pp. 878-909, y «La transformación de la Generalitat Medieval», Obra Dispersa, I, Barcelona 1967, pp. 30-43; J.A. SeSmA MuÑoz, La Diputación del reino de Aragón en la época de Fernando // (1479-1516), Zaragoza, 1977 se acabará con ese valor adquirido de la misma manera que la Generalitat catalana encabezó la sublevación de Cataluña en 1462 y la Diputación de Aragón patrocina el rechazo de la Inquisición, ambas, al menos durante el siglo XVI, alentaron la política contra los Austrias.

27 T. de Montagut Estiragues, "La administración financiera en la Corona de Aragón», Homenaje al prof. G. de Valdeavellano, Madrid 1982, p. 491. 
organización perfecta se basaba en la existencia de una sola cabeza -el rey-, con un solo vientre - la Hacienda Real- y unos pies -el pueblo-, a un sistema múltiple que él mismo debió aceptar, donde tres cabezas - las tres Diputaciones-, le disputaban el derecho exclusivo de decidir y regían a otros tantos vientres -las Haciendas de los reinosque se nutrían con lo producido por los mismos pies, lo que limitaba considerablemente el poder del monarca y su capacidad de gestión. 
